\title{
NO QUEREMOS MEDIO AMBIENTE, LO QUEREMOS COMPLETO
}

Federico Hederich G. *

Sí bien es evidente la relación HombreMedio Ambiente, no todos tenemos clara la manera como interactuamos interrumpiendo el desarrollo armónico de esta relación.

El primer punto que vamos a tratar pretende esclarecer el significado de dos palabras básicas cuando se trata el tema del medio ambiente, en primera instancia, el término "basura" que se define como inmundincia, estiércol, y luego analizaremos "desperdicio" que significa derroche, residuo.

Si analizamos profundamente estas dos palabras evidencian lo grave de la confusión: con la simple acción de colocar un papel en la caneca de la basura, estamos transformando un residuo reutilizable en un elemento inmundo, en real basura.
El segundo punto se refiere al tratamiento de los desechos. El periódico cuando se termina de leer está limpio, solo cuando lo mezclamos con residuos líquidos, orgánicos o de otra clase lo ensuciamos, esto quiere decir que todo depende del proceso de selección que se realice en el sitio donde se originan los desechos. Sí asuminos con empeño la tarea de reciclar debemos mantener en orden los desechos y observaremos cómo la basura se reduce a su minima expresión.

El tercer punto hace referencia al concepto integral que debe acompañar la preocupación por el medio ambiente. El reciclaje no es la única manera de contri- 
buir. El reciclaje sumado a la reducción de consumos de agua y energía eléctrica y a la reutilización de algunos elementos se traduce en economia del hogar, dinero en efectivo y una conciencia ambiental limpia.

Para justificar lo anterior veamos un ejemplo: solo tomaremos el papel y el cartón, si lo reciclamos no será necesario talar tantos árboles, lo cual protege indirectamente las laderas de los rios, las fuentes de agua, se evita la erosión, las sequias y en época de invierno, se previenen inundaciones, adicionalmente se protege la biodiversidad, la calidad del aire que respiramos y contribuimos a dejar como herencia a las futuras generaciones un medio ambiente en buen estado, de lo contrario nos haremos acreedores al título de depredadores y los sueños de los niños de correr por grandes zonas verdes y respirar aire puro se verán reducidos a utópicos ambientes artificiales que dejarán mucho que desear.

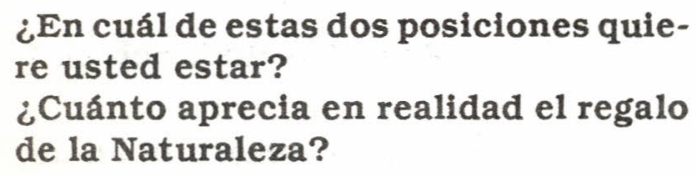
re usted estar? ¿Cuánto aprecia en realidad el regalo de la Naturaleza?

Por otra parte, existen varios consejos prácticos para facilitar los procesos de reciclaje.

- El reciclaje del agua

- El ahorro de energía eléctrica

- Los procesos de reciclaje

Y adicionalmente, el hombre goza de inteligencia, creatividad, y herramientas científico-técnicas para desarrollar politicas y campañas educativas para la protección del medio ambiente. Próximamente se estrenará en Colombia el Ministerio del Medio Ambiente, es bueno que los colombianos estemos listos y preparados para asumir este compromiso.

Pensar que el reciclaje y el ahorro no son rentables, es una posición equivocada, tenemos ejemplos significativos en el mundo de paises altamente desarrollados, ¿Cuánto tenemos que esperar para empezar a actuar?, ¿o es necesario llegar a un punto crítico?

Recordemos que los daños ambientales son irreversibles. ACTUA. 